\title{
REFORMA DO ENSINO MÉDIO E A EDUCAÇÃO FíSICA: um abismo para o futuro
}

\author{
Robson dos Santos Bastos' \\ Osvaldo Galdino dos Santos Junior² \\ Marcelo Pereira de Almeida Ferreira ${ }^{3}$
}

\section{RESUMO}

Desenvolve análises sobre a reforma do ensino médio proposto pela Medida Provisória n. 746, hoje Lei 13.415/17, e suas implicações no futuro da Educação Física. Parte da seguinte pergunta científica: Quais as perspectivas para o futuro da Educação Física diante da reforma do ensino médio proposta pela nova política educacional? Como estratégia metodológica desenvolveu-se um estudo documental, tendo como fonte de análise os textos da Medida Provisória e da Lei que a ratifica, além das notas publicadas por diferentes entidades ligadas à Educação e à Educação Física. O estudo indica que a reforma do ensino médio implicará significativamente na Educação Física em três campos: no seu ensino na educação básica, na formação do professor e no trabalho docente.

Palavras-chave: Política Educacional. Reforma do Ensino Médio. Educação Física.

1 Doutorando em Educação. Professor da Faculdade de Educação Física da Escola Superior Madre Celeste (ESMAC). Belém/Pará, Brasil. E-mail: robsonbastos@hotmail.com

2 Mestre em Educação. Professor da rede de ensino da Secretaria de Estado de Educação do Pará (SEDUC/PA). Ananindeua/Pará, Brasil. E-mail: osvaldogaldino@hotmail.com

3 Doutorando em Educação. Professor da Universidade Federal do Pará (UFPA). Castanhal/Pará, Brasil. E-mail: russo.marcelo@uol.com.br 
REFORM OF MEDIUM EDUCATION AND PHYSICAL EDUCATION: an abyss for the future

\section{ABSTRACT}

It develops analyzes on the reform of secondary education proposed by Provisional Measure . 746, now Law 13.415/17, and its implications in the future of Physical Education. Part of the following scientific question: What are the perspectives for the future of Physical Education in the face of the reform of secondary education proposed by the new educational policy? As methodological strategy a documentary study was developed, having as a source of analysis the texts of the MP and the law that ratifies it, besides the notes published by different entities related to education and Physical Education. The study indicates that the reform of high school will imply significantly in Physical Education in three fields: in its teaching in basic education, in teacher training and in teaching work.

Keywords: Educational Policy. High School Reform. Physical Education.

\section{REFORMA DE LA EDUCACIÓN SECUNDARIA Y LA EDUCACIÓN FÍSICA: un abismo para el futuro}

\section{RESUMEN}

Se desarrolla un análisis sobre la reforma de la educación secundaria propuesta por la Medida Provisoria n. 746, hoy la Ley $13.415 / 17$, y sus implicaciones para el futuro de la Educación Física. Parte del siguiente problema científico: ¿Cuáles las perspectivas para el futuro de la educación física en la reforma de la educación secundaria propuesta por la nueva política educativa? Como estrategia metodológica se ha desarrollado un estudio documental, y como fuente de análisis los textos de la Medida Provisoria y la Ley que la ratifica, además de las notas publicadas por diferentes entidades relacionadas a la Educación y la Educación Física. El estudio indica que la reforma de la educación secundaria implica de manera significativa en la Educación Física en tres campos: en la enseñanza en la educación básica, la formación del profesorado y en el trabajo del profesor.

Palabras clave: Política Educativa. Reforma de la Educación Secundaria. Educación Física. 


\section{INTRODUÇÃO}

Em 16 de fevereiro de 2017 o presidente Michel Temer (PMDB) sanciona a Lei $13.415 / 17$, na qual ratifica a reforma do ensino médio proposta por meio de medida provisória elaborada pelo grupo político que tomou o poder do Estado brasileiro por meio de um golpe jurídico-parlamentar, no primeiro semestre de 2016. Desde quando a Medida Provisória (MP) no 746 foi promulgada em setembro de 2016, durante seu processo de tramitação e aprovação na câmara e no senado, até sua homologação como lei em fevereiro do ano corrente, diferentes entidades ligadas à educação, intelectuais renomados, parlamentares de esquerda, trabalhadores da educação e estudantes têm se manifestado contrários à reforma do ensino médio, por conta do retrocesso que ela proporcionará à educação brasileira.

Como forma de protesto contra a MP, centenas de escolas e universidades foram ocupadas em todo o país, inúmeras manifestações foram feitas em muitas cidades, uma marcha da educação foi feita em Brasília, diferentes manifestações de parlamentares no congresso e no senado se colocaram no sentido de impedir sua tramitação. Contudo, pouco se conquistou e as mudanças na Lei de Diretrizes e Bases (LDB) propostas pela MP se mantiveram. O recuo do governo em relação ao texto original se deu apenas em dois aspectos pontuais: (i) a divisão em $60 \%$ do currículo preenchido pela Base Nacional Comum Curricular (BNCC) e 40\% destinado aos itinerários formativos (antes era 50\%/50\%) e o retorno da obrigatoriedade das disciplinas de Educação Física, Arte, Sociologia e Filosofia, que estavam fora do texto original (ficando para ser definido na BNCC como essa obrigatoriedade deverá acontecer - e portanto, se estarão presentes ou não nos três anos do ensino médio). Essas questões preocupam professores, pais, alunos e a sociedade em geral, porque a reforma proposta pelo governo Temer deixa muitas perguntas no ar.

Neste estudo, em particular, buscaremos analisar as implicações da MP na Educação Física e, diante disso, partiremos da seguinte pergunta: quais as perspectivas para o futuro da Educação Física diante a reforma do ensino médio proposta pela nova política educacional?

Para responde-la, desenvolvemos um estudo documental para compreender o objeto em questão. Para além do texto original da MP e da Lei sancionada em fevereiro deste ano, nos utilizaremos também de documentos elaborados por diferentes entidades ligadas à Educação e à Educação Física, nos quais se posicionam contrários à reforma proposta pelo atual governo.

Como caminho teórico buscamos primeiro compreender o contexto político-econômico no qual as mudanças na gestão do Estado brasileiro se deram; em seguida, trataremos sobre as mudanças na LDB proposta pela MP, no sentido de pontuar as concepções implícitas e explícitas no documento que revelam a nova agenda para a educação brasileira; e, por fim, apresentaremos um conjunto de hipóteses que revelam as implicações da MP para a Educação Física brasileira, em três campos: no ensino da Educação Física escolar, na formação do professor e no trabalho docente. 


\section{A IMPLEMENTAÇÃO DO PROJETO REJEITADO NAS ÚLTIMAS ELEIÇÕES PRESIDEN- CIAIS NO BRASIL}

A mudança pelo qual a condução do Estado brasileiro passou no ano de 2016 provocou também transformações na maneira como as políticas neoliberais estavam sendo conduzidas no país. Se durante os 14 anos do governo do PT (Lula e Dilma) se buscou promover uma conciliação de classes por meio de políticas neoliberais, garantindo ao mesmo tempo o fortalecimento do modo de produção capitalista e a ampliação das políticas sociais em diferentes setores, hoje o governo Temer se faz valer de políticas "ultraliberais" por meio de uma redução drástica das políticas para o social, ao mesmo tempo em que garante (diante da crise econômica) benefícios que mantêm o pleno desenvolvimento e o lucro das oligarquias do capital nacional e internacional, projeto danoso às conquistas históricas da classe trabalhadora. Os documentos "Ponte Para o Futuro I e II" do PMDB já indicavam que haveria reformas nesse sentido, mesmo rejeitado nas quatro últimas eleições presidenciais no país.

A crise econômica internacional, aprofundada em 2008 pela crise imobiliária nos EUA, atinge de fato o Brasil logo após a reeleição da presidenta Dilma Rousseff em 2014, dando início a uma forte recessão econômica no país, aliado a uma crise política provocada pelos desdobramentos da chamada "Operação Lava Jato" ${ }^{5}$. Para muitos, a crise política, que contribuiu para a mudança na condução da política brasileira, teve início durante as investigações da Polícia Federal sobre essa operação, isso porque colocou em risco a carreira e a liberdade de 50 políticos de seis partidos importantes no país (PT, PSDB, PMDB, PP, SD e PTD) que, diante do perigo eminente, decidem dar início a um conjunto de articulações políticas e jurídicas com o intuito de barrar aquilo que o senador da república Romero Jucá (PMDB) denominou de "sangria"6 em diálogo com um aliado político.

Esse é um dos principais fatores que deram origem à ruptura da institucionalidade democrática por meio do denominado "golpe de Estado jurídico-parlamentar". Para Alves (2016) a profunda crise do capitalismo global e, sobretudo, a crise interclasse da burguesia fez com que o governo Dilma sofresse um conjunto de ações articuladas entre "partidos, movimentos sociais, think tanks e meios de comunicação de massa" (ALVES, 2016, s/p) com a intenção de tirá-la do poder. Para o autor, foram articulações oriundas da "oposição neoliberal, reacionária e oligárquica brasileira" (ALVES, 2016, s/p), ou seja, setores da burguesia que estão hoje ocupando o governo Temer.

4 Vide: ORSO, P. Neoliberalismo: equívocos e consequências. In: LOMBARDE, J.; SANFELICE, J. (Orgs.). Liberalismo e educação em debate. Campinas, SP: Autores Associados, Histedbr, 2007.

5 Operação deflagrada pela Polícia Federal em março de 2014 e que recebeu esse nome por conta das investigações de um grande esquema de lavagem e desvio de dinheiro da Petrobras através de um posto de gasolina, um grande esquema que envolvia grandes empreiteiras do país e políticos importantes, tanto da base de apoio do governo Dilma Rousseff, como da oposição.

6 Ver matéria em: VALENTE, R. Em diálogos gravados, Jucá fala em pacto para deter avanço da Lava Jato. Folha de São Paulo. Brasília, 23 de maio de 2016. Disponível em: <http://www1.folha.uol.com.br/ poder/2016/05/1774018-em-dialogos-gravados-juca-fala-em-pacto-para-deter-avanco-da-lava-jato.shtml > . Acesso em: 01.03.2017. 
Com isso o processo de impeachment da presidenta Dilma Rousseff (PT) foi iniciado em 2 de dezembro de 2015 quando o então Presidente da Câmara dos Deputados, Eduardo Cunha (PMDB), aceitou a denúncia por crime de responsabilidade, feita pelo procurador da justiça aposentado, Hélio Bicudo e pelos advogados Miguel Reale Júnior e Janaína Paschoal. Contudo, o fato de maior visibilidade sobre esse processo se deu no dia 17 de abril de 2016, quando o plenário da Câmara dos Deputados aprovou o relatório em que pedia a cassação do mandato da presidenta em uma sessão transmitida em rede aberta para todo o Brasil, com uma cobertura midiática digna de um grande evento esportivo. O relatório recebeu 367 votos a favor e 137 contrários. Fato parecido voltou a se repetir no dia 12 de maio de 2016, desta vez no Senado, onde o relatório favorável à cassação recebeu 55 votos e outros 22 contra, dando início a abertura do processo de impedimento, resultando no afastamento de Rousseff da presidência e a imediata posse do então vice-presidente Michel Temer (PMDB).

Com a chegada de Temer ao poder tem início a implementação de um conjunto de reformas com a justificativa de tirar o país da crise econômica, entretanto, o que de fato acontece é o início da implementação de uma agenda importante para a oligarquia capitalista nacional e internacional, que promove "a reestruturação reacionária e conservadora do capitalismo brasileiro nas novas condições históricas de dominância do império neoliberal face ao aprofundamento de suas contradições estruturais" (ALVES, 2016, s/p).

Dessa forma, é encaminhado ao congresso nacional diferentes normativas (Projeto de Lei/PL, Projeto de Lei Complementar/PLC, Projeto de Emenda Constitucional/PEC etc.) com o intuito de implementar essa nova agenda capazes de propiciarem a materialidade efetiva e ampla da superexploração da força de trabalho, tais como os projetos já aprovados ou em tramitação, a exemplo da PEC 55/PEC 241 (limites dos gastos públicos), PL 54/2016 (renegociação da dívida dos estados com a União), PEC 287/2016 (Reforma de Previdência) e PEC 300/2016 (Reforma Trabalhista).

Além desses projetos encaminhados ao congresso, o governo Temer também busca promover reformas em diferentes setores por força de MPs. Esse é o caso da reforma no Ensino Médio, que em 22 de setembro de 2016 (Medida Provisória $n^{\circ}$ 746) foi publicada no Diário Oficial da União (DOU), documento que sofreu pequenas alterações, aprovado pelo congresso no dia 8 de fevereiro de 2017, sancionado pelo presidente no dia 16 do mesmo mês e publicado no DOU no dia seguinte agora como Lei 13.415/17.

Vale lembrar que em 2013 o governo Dilma encaminhou ao Congresso Nacional o Projeto de Lei (PL) n. 6840/2013 que também pretendia alterar a LDB de forma similar ao que foi proposto pela MP/746 de Temer. No projeto de Dilma, que chegou a ser aprovado na Comissão Especial da Câmara dos Deputados), estava previsto a implementação da escola de tempo integral no ensino médio, o aumento da carga horária, a redução do currículo, o caráter tecnicista no ensino desta etapa da educação, além da proposição de mudança no currículo dos cursos de formação de professores. 


\section{REFORMA DO ENSINO MÉDIO: UMA PONTE PARA O FUTURO OU PARA O PASSADO?}

Quando Michel Temer, em 14 de novembro de 2016, foi questionado no programa Roda Viva da TV Cultura sobre o que pensava a respeito da reforma do Ensino Médio proposta pelo seu governo, ele respondeu da seguinte forma: "Nós estamos voltando a um passado extremamente útil", uma frase que revela o projeto de seu governo para o Brasil, ou seja, uma ponte para o passado e não para o futuro. Em entrevista concedida ao jornal do Brasil em setembro de 2016, Ricardo Antunes fala sobre o projeto do PMDB de Temer para o futuro do país.O projeto "Ponte para o Futuro", que na verdade é um atalho para o abismo social, diz que vai haver negociado sobre o legislado sem a perda de direitos. Só que é impossível estabelecer o primado negociado sobre legislado que não seja para reduzir direitos. A ideia do governo não é estabelecer o negociado sobre o legislado para avançar nos direitos, é para reduzir os salários, é para flexibilizar a jornada de trabalho, é para intensificar o banco de horas, é para fazer com que haja redução da jornada com redução do salário. (ANTUNES, 2016, s/p).

Entendemos que uma reforma na educação há muito tempo se faz necessária no Brasil, contudo, a que está sendo proposta por Temer está anos luz de distância daquela que vem sendo pautada por diferentes movimentos sociais e acadêmicos ligados à educação. Na verdade, a MP/746 desconsiderou os debates e proposições que permearam as Conferências Nacionais de Educação (CONAE) e o próprio Plano Nacional de Educação (PNE). Esta imposição do atual governo compõe o conjunto de ações políticas que retoma a um passado não muito distante, no tempo de uma educação técnico-profissionalizante que tinha a perspectiva de formar escravos modernos, capital humano preparado para servir aos interesses de quem detém o domínio econômico neste país.

É importante ressaltar que as políticas sociais são indispensáveis ao Estado capitalista, elas ajudam na manutenção da hegemonia burguesa, possibilitando o controle social de uma classe sobre a outra, contudo, em uma democracia (mesmo que capitalista) o Estado não pode estar à disposição de uma única classe, não pode se desresponsabilizar de suas obrigações com as distintas forças sociais.

\footnotetext{
As políticas públicas, particularmente as de carácter social, são mediatizadas pelas lutas, pressão e conflitos entre elas. Assim, não são estáticas ou frutos de iniciativas abstratas, mas estrategicamente empregadas no decurso dos conflitos sociais expressando, em grande medida, a capacidade administrativa e geral para implementar decisões de governo. Capacidade que burocratas contemporâneos têm por hábito chamar "governança". (SHIROMA; MORAES; EVANGELISTA, 2011, p. 8-9, grifo do autor).
}

Por conta disso, vale ressaltar que nas últimas décadas as Conferências Nacionais de Educação (CONAE) e, consequentemente, o Plano Nacional de Educação (PNE), além de diversas audiências públicas e consultorias no sentido de discutir sobre as Diretrizes Nacionais para os diferentes níveis e modalidades educacionais, dentre outras, foram ações de governança elaboradas estrategicamente no decurso dos conflitos sociais para legitimar as políticas neoliberais. A MP de Temer é uma iniciativa abstrata que desconsidera esse 
processo e se pauta na contramão da história.

A Medida Provisória 746/16 (agora Lei 13.415/17) altera grande parte da Lei 9.394/96 (LDB), da Lei 11.494/07 (Fundo de Manutenção e Desenvolvimento da Educação Básica e de Valorização dos Profissionais da Educação - FUNDEB); revoga a Lei 11.161/05 (que dispõe sobre a obrigatoriedade da língua espanhola); e institui a Política de Fomento à Implementação de Escolas de Ensino Médio em Tempo Integral. Além disso, desconsidera a resolução do Conselho Nacional de Educação (CNE) n 6, de 20 de setembro de 2012 que instituiu as Diretrizes Curriculares Nacionais para a Educação Profissional Técnica de Nível Médio, documento este que se aproxima, reitera e valoriza as formulações contidas no documento referência a Conae de 2014.

As mudanças que consideramos significativas na LDB nas quais a atual reforma do ensino médio promove, são as seguintes: a) o aumento gradativo da carga horária de 800h para 1.400h e o incentivo à ampliação da jornada (tempo integral); b) a flexibilização do currículo em cinco ênfases ou itinerários formativos; c) a profissionalização como uma das opções formativas; d) o reconhecimento de profissionais de notório saber ou de graduados sem formação docente na área para atuarem como tal no ensino médio e; e) a obrigatoriedade da Educação Física, Artes, Filosofia e Sociologia no ensino médio, de forma distinta, por meio da Base Nacional Curricular Nacional Comum.

O que de fato está por trás desse aumento é o estimulo à relação público-privado na educação, pois não está claro no texto da Lei de onde serão disponibilizados os recursos para tanto. Além disso, o recém-sancionado Projeto de Emenda Constitucional (PEC) 241/55, que limita os gastos públicos, impossibilitará a contratação de mais profissionais para atender à demanda oriunda desse aumento na jornada, à construção de estruturas necessárias e à aquisição de equipamentos para o desenvolvimento da proposta à formação técnica profissionalizante. O perigo está nas estratégias que a Lei do Ensino Médio possibilita para superar esses limites, sobretudo no que diz respeito à estratégia que pode ser adotada para ampliar a possibilidade de controle da educação pelo setor privado.

A primeira é a potencialização das escolas que já desenvolvem o ensino de tempo integral e por já estarem nesse processo não precisarão de grandes recursos e sim de pequenos reajustes para ter a marca do governo, dessa forma, vão se apropriar do que as comunidades escolares já vêm desenvolvendo e formar verdadeiras ilhas de excelência de ensino (escolas referências) para, desta forma, legitimar a proposta.

A segunda e mais nefasta para o ensino público é o que está proposto no inciso $\S 11^{\circ}$ do Art. 36 da LDB. Nele está explícito a possibilidade de os sistemas de ensino instituírem convênios com instituições privadas, ou seja, a perigosa parceria público-privada, que pode acontecer tanto na matrícula de alunos com financiamento púbico em escolas privadas que disponibilizam de estrutura mínima exigida pela Lei (seja no ensino presencial ou à distância) ou na gestão das escolas públicas de tempo integral potencializadas pela reforma, tendo como referência o modelo norte-americano de "escola charter", escola mantida com recursos públicos, mas com gestão privada.

Na concepção neoliberal, na relação público-privado o papel do Estado deve ser de "[...] retirar-se da provisão das políticas, através da execução direta ou do financiamento, 
com a justificativa de racionalizar recursos que, em muitos casos, o Estado continua financiando os programas, apesar da execução ser privada" (PERONI, 2015, p. 22). No Brasil, a primeira experiência de escola charter teve início em 2005 nas escolas da rede estadual de ensino de Pernambuco, tendo como um dos principais responsáveis o senhor Mendonça Filho (então vice do governador Jarbas Vasconcelos que assumiu a direção do governo após o afastamento do governador para concorrer às eleições para o senado). Durante o mandato de Mendonça Filho no governo de Pernambuco, a implantação dos Centros de Ensino em Tempo Integral (Procentro) se manteve, política esta coordenada pela Secretaria de Educação do Estado, em parceria com o Instituto de CoResponsabilidade pela Educação (ICE), instituição criada na época exclusivamente para esse fim.

Essa experiência recebeu muita atenção da mídia, sendo divulgada por fundações e organizações sociais ligadas à educação (a exemplo do Movimento Todos Pela Educação) como um modelo de escola charter no Brasil, além disso, o modelo pernambucano serviu de exemplo para outros estados e municípios, tais como: Sergipe, Ceará, Piauí e Rio de Janeiro, Goiás, São Paulo e Campinas, que passaram a adotar políticas similares.

No que diz respeito à flexibilização do currículo em cinco itinerários formativos, sobretudo, a profissionalização como uma das opções formativas, essa reforma traz em seu bojo aquilo que Peroni (2016, p. 21) chama de legalização do "apartheid social na educação no Brasil", isso porque, diferente da reforma da década de 1970 que atingia a todos, a atual política só atinge aqueles que estudam na escola pública, negando conhecimentos relevantes à formação integral do aluno. A reforma ainda determina que o ensino da língua portuguesa e da matemática serão obrigatórios nos três anos do ensino médio e deixa as demais disciplinas, a respeito da forma de sua obrigatoriedade, para serem definidas pela BNCC, ou seja, não está claro se as demais áreas do conhecimento escolar (dentre elas a educação física, artes, filosofia e sociologia) serão obrigatórias nos três anos dessa etapa de ensino.

A grande questão em deixar isso para depois é que o conteúdo da BNCC estava num processo de consulta pública, de diálogo com diferentes setores ligados à educação, processo este que foi interrompido com a mudança de governo e substituído pelas ações de gabinete dos atuais dirigentes do MEC e, portanto, as demais áreas de conhecimento (com exceção da língua portuguesa e da matemática) poderão ter sua carga horária reduzida e algumas (dentre elas a Educação Física, Arte, Filosofia e Sociologia) serem limitadas apenas ao primeiro ano do ensino médio.

Para justificar essa proposta o MEC utiliza a avaliação do Índice de Desenvolvimento da Educação Básica (IDEB) aliada ao argumento abstrato e tendencioso de que um currículo com 13 disciplinas não torna a educação atraente para o aluno digital, pois para eles este aluno não aguenta mais uma escola conteudista, portanto, criam na subjetividade do aluno o fetiche da escolha sobre quais conhecimentos devem adquirir na formação escolar, dando oportunidade também de optar por uma formação profissional, para ingressar a curto prazo

7 Mais informações sobre essa experiência de Escolas Charters em Pernambuco, na perspectiva da Fundação Itu em: DIAS, M. C. N,; GUEDES, P. M. O modelo de escola charter: a experiência de Pernambuco. São Paulo: Instituto Fernand Braudel de Economia Mundial: Fundação Itaú Social, 2010. 
no mercado de trabalho deixando claro ao aluno da escola pública a formação superior não é o caminho a ser seguido.

Para Frigotto (2016) a flexibilização do currículo proposta pela reforma do Ensino Médio de Temer e a equipe de Mendonça Filho é

\begin{abstract}
Uma traição aos alunos filhos dos trabalhadores, ao achar que deixando que eles escolham parte do currículo, vai ajudá-los na vida. Um abominável descompromisso geracional e um cinismo covarde, pois seus filhos e netos estudam nas escolas onde, na acepção de Desttut de Tracy, estudam os que estão destinados a dirigir a sociedade. Uma reforma que legaliza a existência de uma escola diferente para cada classe social. Justo estes intelectuais que em seus escritos negam a existência das classes sociais. (FRIGOTTO, 2016, s/p).
\end{abstract}

Como parte complementar desse processo dual de escola (uma escola para classe dirigente e outra para classe dirigida) a reforma do Ensino Médio ainda altera o Art. 61 da LDB que passa a considerar "profissionais com notório saber" para ministrar na educação escolar básica conteúdos de áreas afins à sua formação ou experiência profissional.

Sobre essa questão a Associação Nacional pela Formação dos Profissionais da Educação (ANFOPE, 2016, p. 2)

Repudia o ataque frontal empreendido à formação e à valorização dos profissionais da educação, uma vez que a MP, ao instituir a contratação de pessoas sem formação específica para o exercício da docência, sem concurso público de provas e títulos, desde que tenham alegado "notório saber", reforça a desqualificação e a desprofissionalização dos professores, com impactos negativos na qualidade do ensino aviltando, sobretudo, a formação, a carreira e os salários do magistério.

Para o Sindicato Nacional dos Docentes do Ensino Superior (2016, p. 10),

\begin{abstract}
Além de desqualificar os cursos de licenciatura, a contrarreforma do ensino médio desrespeita e desvaloriza a profissão do docente, regulamentada e exercida por profissionais que possuem formação específica, com formação pedagógica e domínio de conteúdo, visto que admite que as aulas sejam ministradas por "pessoas com notório saber". A medida diminui o papel do professor na formação dos estudantes, em todos os níveis de ensino, e ignora a importância da formação superior específica para educação na Educação Básica.
\end{abstract}

Temos que considerar ainda que a reforma atinge também o Ensino Superior, haja vista que inclui no Art. 62 da LDB (que trata sobre a formação dos profissionais que atuam na educação básica) um inciso que determina a BNCC como referência no desenvolvimento dos currículos dos cursos de formação de professores, provocando um aumento da superficialidade na formação de professores, por meio da precarização ou extinção do tripé ensino-pesquisa-extensão, além do estímulo à privatização também do ensino púbico, 
haja vista o aumento da parceria público-privado como justificativa para superar os limites orçamentários provocados pela "PEC dos gastos públicos".

Logo após a publicação da MP, diferentes entidades e movimentos sociais ligados à educação, tais como Anfope ${ }^{8}$, Anped $^{9}$, Andes-SN ${ }^{10}$, Conif $^{11}, \mathrm{SBPC}^{12}, \mathrm{CNTE}^{13} \mathrm{FNE}^{14}, \mathrm{UNE}^{15}$, Ubes $^{16}$, ANPG ${ }^{17}$, dentre outras, se posicionaram contrárias à política educacional do governo Temer e declarando apoio ao Movimento Nacional em Defesa do Ensino Médio.

Dentre essas a Anfope (2016, p. 2) se manifestou afirmando que,

Essa é mais uma medida autoritária de um governo ilegítimo que, irresponsavelmente, ameaça a institucionalidade democrática, reduz o direito à educação e nega a luta, a mobilização e as conquistas históricas das entidades que defendem a formação do professor da educação básica na universidade.

Também em contrariedade à reforma, a Anped (2016, s/p) afirmou que

A MP fragiliza o princípio do Ensino Médio como direito de todo cidadão a uma formação plena para a cidadania e o trabalho, abre canais para a mercantilização da escola pública e evidencia a face mais perversa do golpe contra a sociedade brasileira, os estudantes, seus professores e a educação pública.

O Andes-SN (2016, s/p) afirmou que as alterações que a MP promove na LDB "são tão ilegítimas quanto o governo que as impõe!", pois desconsidera o que as diferentes entidades ligadas à educação têm acumulado ao longo dos anos. Afirma ainda que "as propostas apresentadas, desta forma autoritária, refletem, de maneira explícita, a finalidade de atuação deste governo que é unicamente servir ao grande capital de modo rápido, bárbaro e violento." (ANDES-SN, 2016, s/p).

Todas essas manifestações revelam o que está implícito e explicito no conjunto das reformas que estão sendo propostas pelo governo Temer, sobretudo, a Lei 13.415/17, pois se trata de uma política educacional que tem como meta a comercialização da educação brasileira, a destruição do ensino público e a precarização da carreira docente.

\footnotetext{
8 Associação Nacional Pela Formação dos Profissionais da Educação.

9 Associação Nacional de Pós-graduação e Pesquisa em Educação.

10 Sindicato Nacional dos Docentes das Instituições de Ensino Superior.

11 Rede Federal De Educação Profissional, Científica e Tecnológica.

12 Sociedade Brasileira para o Progresso da Ciência.

13 Confederação Nacional dos Trabalhadores da Educação.

14 Fórum Nacional de Educação.

15 União Nacional dos Estudantes.

16 União Brasileira dos Estudantes Secundaristas.

17 Associação Nacional de Pós-graduandos.
} 


\section{AS IMPLICAÇÕES DA LEI 13.415/17 NA EDUCAÇÃO FÍSICA}

De acordo com o exposto até aqui, desde quando a então MP 746 foi promulgada em 22 de setembro de 2016, diferentes entidades ligadas à educação se manifestaram contrárias a essa proposta, manifestações nas quais pontuaram o que essa política representa para a educação brasileira. No campo da Educação Física (assim como nas demais áreas atingidas pela MP) entidades como o Colégio Brasileiro de Ciência do Esporte (CBCE), Executiva Nacional dos Estudantes de Educação Física (ExNEEF), Movimento Nacional Contra a Regulamentação do Profissional de Educação Física (MNCR), Conselho Federal de Educação Física (CONFEF), dentre outros também se manifestaram contra a MP 746.

Dentre estas, destacamos o posicionamento do CBCE e do CONFEF sobre a então retirada da Educação Física do currículo do Ensino Médio. Destacamos essas duas instituições por entendermos que, apesar de serem manifestações contrárias à política proposta, revelam concepções diferentes sobre o papel da Educação Física na educação básica.

Para o CBCE (2016), que aborda o ensino da Educação Física a partir de uma perspectiva mais contemporânea,

[...] essa medida negará aos estudantes a oportunidade de apropriarem-se daqueles saberes que proporcionam a leitura, compreensão e produção das práticas corporais, entendidas como formas de expressão dos grupos sociais. Isso significa a impossibilidade de conhecer, desfrutar e transformar uma parcela do repertório cultural disponível (CBCE, 2016, p. 1).

Já o CONFEF (2016), que ainda entende o ensino da Educação Física a partir de uma concepção higienista, considera

[...] um contrassenso que no momento em que inúmeras pesquisas apontam o crescimento da obesidade e do sedentarismo infanto-juvenil, e sabendo que a atividade física é a medida mais eficaz para evitar esse mal, o Governo Federal proponha a retirada da Educação Física do Ensino Médio. Sobretudo por se tratar do país que acabou de atravessar a década de megaeventos esportivos, sediando recentemente os Jogos Olímpicos e Paraolímpicos, onde ficou clara a importância da atividade física na manutenção da saúde e da formação cidadã (CONFEF, 2016, p. 1).

No texto original da MP, a Educação Física - assim como Arte, Filosofia e Sociologia - foi retirada do currículo do ensino médio. Desta forma, o repúdio do CBCE, compartilhado também, em expressão de fundo, pelas manifestações da ExNEEF e MNCR, tiveram em comum o entendimento de que a retirada dessas disciplinas significa a negação do direito ao conhecimento geral que possibilite a formação crítica com acesso pleno ao desenvolvimento intelectual, afetivo, físico, moral e social, possibilidades estas que a Educação Física juntamente com as demais disciplinas, pode oferecer ao alunos.

Já o CONFEF, ainda que também se posiciona contra a MP, expressa a defesa da Educação Física na escola unicamente na função de cuidado com a saúde, associando-a 
aos megaeventos esportivos (Jogos Olímpicos e Paralímpicos e Copa do Mundo), como se fossem preceitos ao incentivo da prática da atividade física e esporte por parte da população, sobretudo na escola. Portanto, não considera que a maioria do investimento público destinado ao esporte concentra-se em uma única dimensão do esporte - rendimento - deixando as demais dimensões sociais - lazer e popular - sem grandes investimentos, assim sendo, são argumentos que mais justificariam a MP do que o seu contrário.

Dentre as mudanças que a MP propõe na LDB, o retorno da obrigatoriedade dessas disciplinas (inicialmente suprimidas do currículo) foi um dos poucos recuos conquistados pela mobilização nacional. Contudo, a estratégia adotada pelo MEC de deixar para a BNCC a decisão de como essa obrigatoriedade irá acontecer deixa claro que essa vitória não é plena, tendo em vista que há indícios de que não haverá uma ampla discussão no processo de elaboração desse documento. Logo, corre-se o sério risco de haver inúmeras implicações para as disciplinas que não estão postas como obrigatórias nos três anos do Ensino Médio, seja no desenvolvimento do ensino, na formação do professor e no trabalho docente.

No campo da Educação Física, diante dos aspectos que foram apresentados neste estudo, podemos tratar como hipótese sobre essas implicações na educação básica, na formação do professor e no trabalho docente:

a) No ensino: tornar-se-á secundarizada perante outras disciplinas no currículo escolar, pois, diferentemente de português e matemática, não está claro em que momento dos três anos a Educação Física será obrigatória. De concreto, a Lei determina sua obrigatoriedade nos $60 \%$ da BCNN (não necessariamente nos $100 \%$ desse total), além disso, os estudantes terão um currículo flexível, com opção de escolha sobre o itinerário formativo sobre os outros $40 \%$ do currículo, mas se o aluno optar pela Educação Profissional não terá a Educação Física, já que esta se encontra na área de Linguagens. Outro engodo a destacar são as próprias avaliações educacionais que darão maior atenção à carga horária da base comum, logo, a formação poderá desconsiderar as peculiaridades regionais ou as histórias das cidades.

Isso nos revela que ocorrerá a redução da carga horária da Educação Física nesta etapa de ensino. Tem-se, assim, uma perda significativa sobre a possibilidade do estudante do Ensino Médio elevar sua consciência por meio da reflexão das práticas corporais que, longe de serem ingênuas, têm relação direta com a ordem social contemporânea.

Outro aspecto importante será o retorno da valorização de conteúdos técnicos-esportivos, por conta do ambiente técnico-profissionalizante que se pretende instituir nas escolas públicas, um claro retorno à proposta esportivista desenvolvida nas escolas entre as décadas de 1960 e 1980, ação pedagógica que estava em consonância com o modelo educacional objetivo e operacionalizante demandado pelo mercado de trabalho. A diferença é o modelo de educação de outrora era para toda sociedade e hoje está proposto apenas para os estudantes da educação pública, ou seja, uma proposta claramente dualista de educação;

b) Na formação do professor: entendemos que haverá uma redução significativa de cursos de licenciatura em Educação Física e o consequente aumento de cursos de bacharelado. Isso deve se dar por conta da redução da demanda de profissionais para atuar na Educação Física escolar do ensino público e ainda pela possibilidade 
de agora o bacharel, o ex-atleta ou o provisionado em educação física, considerados pela Lei 13.415/17 profissionais com notório saber, atuarem também no campo escolar (antes a LDB não permitia essa possibilidade). Além disso, aumentará a fragmentação entre esses dois campos de formação e o conflito entre os profissionais da área (licenciado e bacharel).

Outro aspecto importante no campo da formação será a desvalorização/secundarização de conhecimentos relacionados às ciências humanas no currículo dos cursos de formação e, por conseguinte, à retomada da valorização das práticas técnicas esportivas muito comuns nas décadas de predomínio do tecnicismo na educação brasileira. Temos essa compreensão por entender que, em relação à BNCC, o atual governo não buscará democratizar o debate, mas o tratará nos gabinetes do MEC. Portanto, tenderá a seguir a lógica de retomada do ensino tecnicista proposto na Lei $13.415 / 17$, haja vista que o novo inciso $\left(\S 8^{\circ}\right.$ ) incluído no Art. 62 da LDB/96, determina que "os currículos dos cursos de formação de docentes terão por referência a Base Nacional Comum Curricular". Ou seja, a concepção de educação destinada para a educação básica determinará também a formação do professor.

c) No trabalho do professor: se confirmando a não obrigatoriedade do ensino da Educação Física nos três anos do ensino médio, consequentemente, poderá haver uma redução significativa da carga horária e da remuneração dos professores que já atuam nesta etapa de ensino. Aliado a isso, a contratação de profissionais com notório saber para atuarem no ensino da Educação Física colaborará para a redução de vagas de docentes no ensino público a novos professores graduados, além de criar uma disputa entre esses trabalhadores (graduados e profissionais com notório saber).

O profissional com notório saber corre o risco de se submeter a relações de trabalho extremamente desfavoráveis, com salário menor do que é determinado pelo piso nacional dos professores, além de outras desvantagens trabalhistas por não ser professor (mesmo considerando a exigência de formação complementar para a atuação no campo da docência). Portanto, corremos o sério risco de testemunharmos a precarização do trabalho do professor no ensino público, tendo suas conquistas históricas na carreira docente desconsideradas ou revogadas, sobretudo se a reforma trabalhista for aprovada da forma como está sendo proposta pelo atual governo.

Por fim, o trabalho do professor de Educação Física na escola corre o sério risco de voltar a ser comparado ao de treinador, por conta da retomada da concepção tecnicista/ esportivista como proposta orientadora de sua ação pedagógica, isso porque o discurso técnico-profissionalizante, muito comum nas décadas de 1960 a 1980, passará a ser estimulado pelo discurso oficial nas escolas públicas.

\section{CONSIDERAÇÕES}

Neste estudo buscamos revelar os aspectos que compõem a nova política educacional brasileira, desde os fatos políticos que compuseram a troca na coordenação do Estado 
brasileiro, as reformas que estão em andamento no país, sobretudo a reforma voltada para a educação, até as hipóteses sobre as implicações dessas reformas para a Educação Física brasileira. Compreendemos que as mobilizações estão ocorrendo no sentido de se contrapor, de agir e de propor outras possibilidades, contudo, parece que a força, a representação ou a organização não está sendo suficiente para provocar uma interrupção ou tornar mais difícil o desenvolvimento das intenções políticas do atual governo para o futuro do país.

A mobilização nacional oriunda de diferentes entidades ligadas à educação, também está em tramitação no Ministério Público Federal uma Ação Direta de Inconstitucionalidade (ADIN n. 5.599) feita pela bancada do Partido Socialismo e Liberdade (PSOL) na Câmara Federal contra esta ação oriunda da Presidência da República. Entendemos que ações como essas da bancada de deputados e as manifestações institucionais das entidades contrárias à reforma do Ensino Médio promovida pelo atual governo são importantes, mas que na atual conjuntura política na qual o governo goza de um apoio expressivo no congresso e no senado, torna mais difícil a reversão desse quadro. Contudo, temos a convicção de que só com uma mobilização nacional de diferentes categorias profissionais, movimento estudantil, partidos políticos e movimentos sociais em uma ação unificada poderá transformar essa realidade.

É necessário construir uma mobilização nacional e uma greve geral, não só da educação, mas de todos os setores para que as reformas que buscam destruir conquistas históricas da classe trabalhadora possam ser mantidas ou ampliadas. O conjunto de reformas vai atingir a todos, portanto, a luta é de todos, neste sentido, todos têm que entender a necessidade de se constituir uma consciência de classe e promover a mobilização necessária para a garantia dos direitos conquistados.

\section{REFERÊNCIAS}

ANTUNES, Ricardo. Período que vai de 2016 a 2018 será uma sucessão amplificada articulada de crises. Jornal do Brasil, 5 set. 2016. Disponível em: < http://www.jb.com. br/pais/noticias/2016/09/04/brasil-vai-entrar-numa-epoca-de-manifestacoes-sindicais-esociais-diz-sociologo/>. Acesso em: 01.02.2017.

ALVES, Giovanni. O golpe de 2016 no contexto da crise do capitalismo neoliberal. Blog da Boitempo, 08 jun. 2016. Disponível em: < https://blogdaboitempo.com. br/2016/06/08/o-golpe-de-2016-no-contexto-da-crise-do-capitalismo-neoliberal/> . Acesso em: 03.02.2017.

ANDES-SN. Nota de repúdio à Contrarreforma do Ensino Médio imposta pela MP 746/16.

Brasília, 26 set. 2016. Disponível em: < http://www.andes.org.br/andes/print-ultimasnoticias.andes? id =8379>. Acesso em: 22.01.2017

ANDES-SN. MP 746/2016 compromete todo o sistema educacional brasileiro. Informa ANDES, informativo $n^{\circ}$ 63, Brasília, out. 2016.

ANFOPE. Manifesto contra a medida provisória n. 746/2016. Faculdade de Educação da UFBA, Salvador/BA, 17 out. 2016. Disponível em: < http://www.faced.ufba.br/sites/ faced.ufba.br/files/manifesto_anfope_mp_12.10.2016r.pdf > . Acesso em: 01.03.2017. 
ANPED. Nota pública da ANPEd sobre a Medida Provisória do Ensino Médio MP do Ensino Médio - Autoritária na forma e equivocada em conteúdo. Rio de Janeiro, 23 set. 2016. Disponível em: < http://www.anped.org.br/news/nota-publica-da-anpedsobre-medida-provisoria-do-ensino-medio > . Acesso em: 05.03.2017.

BRASIL. Lei n. 13.415. Brasília, 16 fev. 2017. Disponível em: < http://www.planalto.gov. br/ccivil_03/_ato2015-2018/2017/lei/L13415.htm >. Acesso em: 10.02.2017.

CBCE. Nota de repúdio. Diretoria Nacional do Colégio Brasileiro de Ciências do Esporte; Curitiba, PR, 23 set. 2016. Disponível em: < http://www.cbce.org.br/upload/files/ NOTA_REPUDIO_CBCE_1.pdf >. Acesso em: 05.03.2017.

FRIGOTTO, G. Reforma de ensino médio do (des) governo de turno: decreta-se uma escola para os ricos e outra para os pobres. AVALIAÇÃO EDUCACIONAL - Blog do Freitas, 23 set. 2016. Disponível em: < https://avaliacaoeducacional.com/2016/09/23/ frigotto-segregacao-aprofundada/ $>$. Acesso em: 12.12.2016.

PERONI, V. Implicações da relação público-privado para a democratização da educação no Brasil. In: PERONI, V. Diálogos sobre as redefinições no papel do Estado e nas fronteiras entre o público e o privado na educação. São Leopoldo, RGS: Oikos, 2015. p. 15-34. SHIROMA, E.; MORAES M. C.; EVANGELISTA O. Política educacional. Rio de Janeiro: Lamparina, 2011.

Recebido em: abril/2017

Aprovado em: julho/2017 